\title{
Regiospecificity in Deuterium Labeling Determined by Mass Spectrometry
}

\author{
Alfonso Loaiza* and Francisco Zaera \\ Department of Chemistry, University of California, Riverside, California, USA
}

\begin{abstract}
Several mass spectrometry methods were explored to determine the regiospecificity of deuterium substitutions in hydrocarbon mixtures. The case investigated in this work was that of ethane mixtures obtained by catalytic $\mathrm{H}-\mathrm{D}$ exchange between either $\mathrm{C}_{2} \mathrm{H}_{6}$ and $\mathrm{D}_{2}$ or $\mathrm{C}_{2} \mathrm{D}_{6}$ and $\mathrm{H}_{2}$ over platinum surfaces. A total of ten isotopologs are possible, and were indeed detected in all cases. Deconvolution of low-resolution mass spectra was found sufficient to determine the composition of the gas mixtures in terms of the total number of deuterium substitutions, but not to identify symmetric versus asymmetric substitutions in the $\mathrm{C}_{2} \mathrm{D}_{2} \mathrm{H}_{4}$, $\mathrm{C}_{2} \mathrm{D}_{3} \mathrm{H}_{3}$, and $\mathrm{C}_{2} \mathrm{D}_{4} \mathrm{H}_{2}$ products. High-resolution mass spectrometry allowed the separation of the intensities due to $\mathrm{C}_{2} \mathrm{X}_{4}{ }^{+}$fragments from those from molecular $\mathrm{C}_{2} \mathrm{X}_{6}{ }^{+}$signals $(\mathrm{X}=\mathrm{H}$ or $\mathrm{D})$, and with that for a more accurate determination of the composition of the mixtures. Relative probabilities were determined for the symmetric versus asymmetric removal of $\mathrm{X}_{2}$ from $\mathrm{C}_{2} \mathrm{X}_{6}{ }^{+}$ ions and for isotope scrambling in the mass spectrometer, and with that information fairly good cracking patterns were then calculated for the $\mathrm{C}_{2} \mathrm{X}_{4}{ }^{+}$fragments produced by each individual pure $\mathrm{C}_{2} \mathrm{X}_{6}$ isotopologue. However, total deconvolution of all ten components in the ethane mixtures obtained by $\mathrm{H}-\mathrm{D}$ exchange catalysis was beyond the experimental accuracy of the measurements. Tandem mass spectrometry/collision-induced decomposition mass spectrometry (MS/CID-MS) proved more useful for this task. In particular, it was possible to determine the proportion of symmetric versus asymmetric double $\mathrm{H}-\mathrm{D}$ exchange in samples for which the total ethane- $d_{2}$ (in the case of $\mathrm{C}_{2} \mathrm{H}_{6}+\mathrm{D}_{2}$ ) or ethane- $d_{4}$ (with $\mathrm{C}_{2} \mathrm{D}_{6}+\mathrm{H}_{2}$ ) amounted to only $\sim 3 \%$ on the ethane mix. A comparison with other analytical methods, NMR in particular, is provided. (J Am Soc Mass Spectrom 2004, 15, 1366-1373) (C) 2004 American Society for Mass Spectrometry
\end{abstract}

I sotope labeling, deuterium marking in particular, is one of the most widespread methods in studies of molecular structures and reaction mechanisms [1-4]. Because such labeling relies on the substitution of atoms with the same chemical properties but different atomic mass, mass spectrometry is often the analytical tool of choice [5]. Much work has indeed been carried out to date on mass spectrometry detection of deuterium-labeled molecules [6]. However, while it is quite straightforward to determine the number of hydrogen atoms substituted by deuterium in a particular molecule, it is much more difficult to identify the specific moieties where the substitutions have taken place. Sometimes that information is embedded in the cracking patterns of the mass spectra, provided that the resulting fragments can be cleanly associated with specific moieties of the molecule, but isotope scrambling during the ionization process prior to mass selection complicates matters even in those cases.

\footnotetext{
Published online August 6, 2004

Address reprint requests to Dr. Professor F. Zaera, Department of Chemistry, University of California, Riverside, CA 92521, USA. E-mail: Francisco.zaera@ucr.edu

*Permanent address: Departamento de Química, Universidad de los Andes, Mérida, Venezuela.
}

Here we report on studies carried out to evaluate the performance of different mass spectrometry techniques for the identification of the location of the deuterium substitutions in mixtures of isotopically labeled compounds. Our work was carried out with ethane and aimed to identify the mechanism of $\mathrm{H}-\mathrm{D}$ exchange reactions catalyzed by platinum surfaces, but our conclusions may be extrapolated to other molecules and other applications. Three techniques were applied in this work, namely, low- and high-resolution mass spectrometry (LR-MS and HR-MS) and tandem mass spectrometry/collision-induced decomposition mass spectrometry (MS/CID-MS). While all three techniques were capable of providing the composition of the ethane mixtures as a function of the number of hydrogens exchanged by deuteriums, only the last was useful in determining the regiospecificity of the substitutions. A discussion is provided on the relative performance of mass spectrometry versus NMR for the task of deuterium-labeling determinations.

\section{Experimental}

Low-resolution mass spectra (LR-MS) of the ethane samples produced by catalytic exchange were obtained 
in line during reaction using a computer-interfaced Dycor MA-200M quadrupole mass spectrometer with an electron-impact ionizer operated at $70 \mathrm{eV}$ ionization energy. The gas samples were flowed continuously into the mass spectrometer via a capillary tube connected to the main micro-batch reactor used for the reaction. High-resolution mass spectra (HR-MS) were acquired using a Finnigan-MAT 900 spectrometer operated at 70 $\mathrm{eV}$ ionization energy and $180{ }^{\circ} \mathrm{C}$ source temperature. The static resolving power of that instrument (Da value over full with at $10 \%$ of maximum) was set to approximately 25,000 by using the 79 Da doublet of a 1:9 mixture of benzene:pyridine. Tandem mass spectrometry/collision-induced decomposition (MS/CID-MS) sample analysis was carried out with a VG ZAB 2FHF high-resolution reversed-geometry mass spectrometer. The electron-impact ionizer was set at $70 \mathrm{eV}$ ionization energy, $200{ }^{\circ} \mathrm{C}$ source temperature, and 1000 resolving power. MS/MS spectra were obtained by sequential mass filtering using the magnetic sector of the instrument, fragmentation of the ion of interest in the intermediate field-free region via gas-phase collisions through a $5.5 \times 10^{-6}$ torr He atmosphere, and second mass filtering using an electrostatic ionizer.

Pure normal ethane (ethane- $\left.d_{0}\right)\left(\mathrm{C}_{2} \mathrm{H}_{6}\right.$, Matheson, Montgomeryville, $\mathrm{PA}, 99.9 \%$ ), and $\mathrm{CH}_{3} \mathrm{CH}_{2} \mathrm{D}$ (ethane$\left.d_{1}\right), \mathrm{CH}_{3} \mathrm{CHD}_{2}$ (ethane- $\left.d_{2, \mathrm{a}}\right), \mathrm{CH}_{2} \mathrm{DCHD}_{2}$ (ethane- $d_{3, \mathrm{~s}}$ ), $\mathrm{CH}_{3} \mathrm{CD}_{3} \quad$ (ethane- $\left.d_{3, \mathrm{a}}\right), \quad \mathrm{CH}_{2} \mathrm{DCD}_{3}$ (ethane- $d_{4, \mathrm{a}}$ ), $\mathrm{CHD}_{2} \mathrm{CHD}_{2}$ (ethane- $d_{4, \mathrm{~s}}$ ), $\mathrm{CHD}_{2} \mathrm{CD}_{3}$ (ethane- $d_{5}$ ), and $\mathrm{C}_{2} \mathrm{D}_{6}$ (ethane- $d_{6}$ ) (Merck-Canada or CIL, Andover, MA, $99 \%$ atom purity), were used as supplied. Two ethane mixtures were produced by $\mathrm{H}-\mathrm{D}$ exchange using a platinum foil (Aldrich, Milwaukee, WI, 99.99\% purity) as catalyst and a micro-batch reactor described elsewhere [7-9]. Mixtures of either 50 torr of normal $\mathrm{C}_{2} \mathrm{H}_{6}$ and 500 torr of $\mathrm{D}_{2}$ or 50 torr of $\mathrm{C}_{2} \mathrm{D}_{6}$ and 500 torr of $\mathrm{H}_{2}$ were reacted, at 625 and $675 \mathrm{~K}$ respectively, until reaching 37 and $55 \%$ total conversions. The gas mixtures were trapped into a U-shaped glass tube with valves at each end by means of liquid nitrogen cooling, and pumped while frozen in order to remove the hydrogen and deuterium gases before leaking them into the mass spectrometers. Finally, an equimolar mixture of six of the pure ethane molecules available to us (ethane- $d_{1}+-d_{2, \mathrm{a}}+-d_{3, \mathrm{a}}+-d_{4, \mathrm{a}}+-d_{5}+-d_{6}$ ) was prepared using the same circulation loop in the microbatch reactor.

\section{Results}

As stated above, LR-MS spectra were taken continuously during the catalytic conversion of the ethane + hydrogen/deuterium mixtures in order to follow the kinetics of the reaction by recording the signals in the 24-36 Da mass spectral range as a function of time. Deconvolution of the data was done by using the experimental cracking patterns of the pure ethane isotopologs available to us and calculated spectra of the rest using a previously reported methodology [10]. It

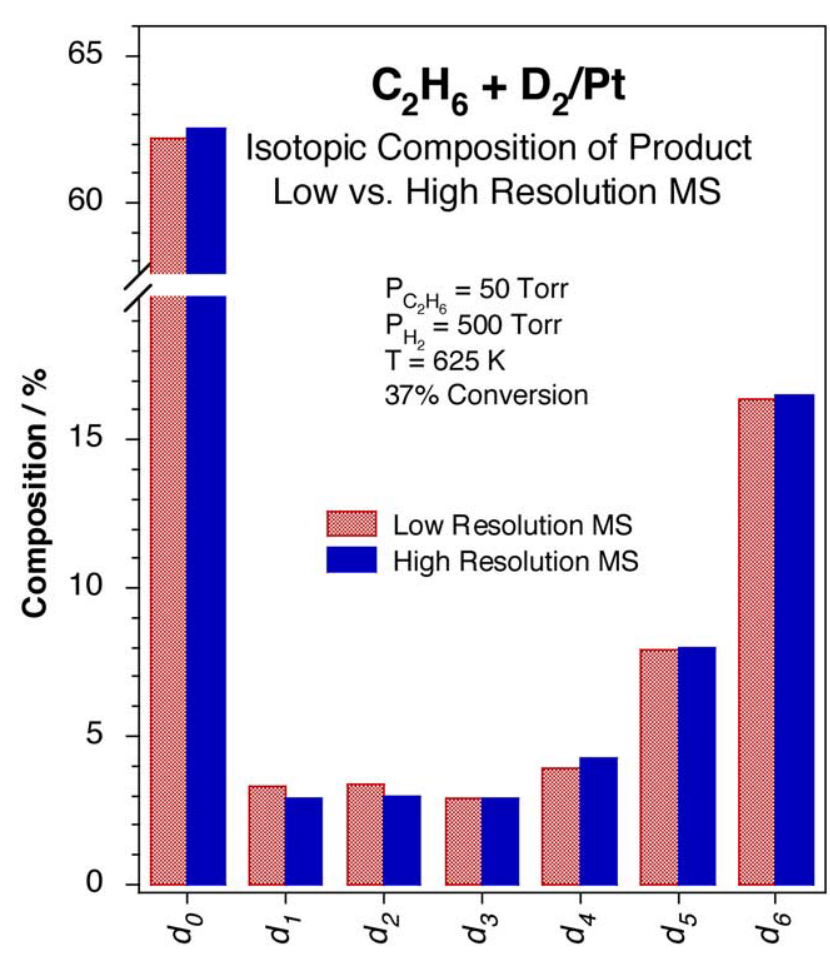

Figure 1. Comparison between the high- and low-resolution mass spectra recorded for a 50 torr $\mathrm{C}_{2} \mathrm{H}_{6}+500$ torr $\mathrm{D}_{2}$ reaction mixture after about $37 \% \mathrm{H}-\mathrm{D}$ exchange over a platinum catalyst. Both techniques are capable of providing information on the composition of the mixture in terms of total number of deuterium substitutions per molecule, but neither is useful for the determination of the regiospecificity of the substitutions in the ethane- $d_{2}$, $-d_{3}$, and $-d_{4}$ components. Comparable values were obtained with both techniques for the total conversion, and similar bimodal product distributions were seen as well. Notice, however, that the low-resolution instrument slightly overestimates the amount of light alkanes produced.

was found that even though the LR-MS data tends to overestimate the amount of light ethanes produced, it reproduces the overall conversion and general isotopologue distribution curves reasonably well, in particular the percentages of each of the components in terms of the total number of deuterium substitutions [7]. A U-shaped distribution was found in all cases, with maxima at one $\left(d_{1}\right)$ and six $\left(d_{6}\right)$ and a minimum at three $\left(d_{3}\right)$ atoms per ethane molecule. A typical result for the case of the 50 torr $\mathrm{C}_{2} \mathrm{H}_{6}+500$ torr $\mathrm{D}_{2}$ mixture after $37 \%$ conversion is provided in Figure 1. On the other hand, given the close similarity of the mass spectrometry cracking patterns of the symmetrically- versus asymmetrically substituted isotopologues, no attempt was made to differentiate between the two isomers of ethane- $d_{2}\left(\mathrm{CDH}_{2} \mathrm{CDH}_{2}\right.$ versus $\left.\mathrm{CD}_{2} \mathrm{HCH}_{3}\right)$, ethane- $d_{3}$ $\left(\mathrm{CD}_{2} \mathrm{HCDH}_{2}\right.$ versus $\left.\mathrm{CD}_{3} \mathrm{CH}_{3}\right)$, or ethane- $d_{4}$ $\left(\mathrm{CD}_{2} \mathrm{HCD}_{2} \mathrm{H}\right.$ versus $\left.\mathrm{CD}_{3} \mathrm{CDH}_{2}\right)$.

The viability of HR-MS for the complete analysis of the isotopically labeled ethane samples was tested next. High-resolution mass spectra were recorded first for each of the pure ethane isotopologues as well as for the equimolar mixture mentioned in the Experimental Sec- 


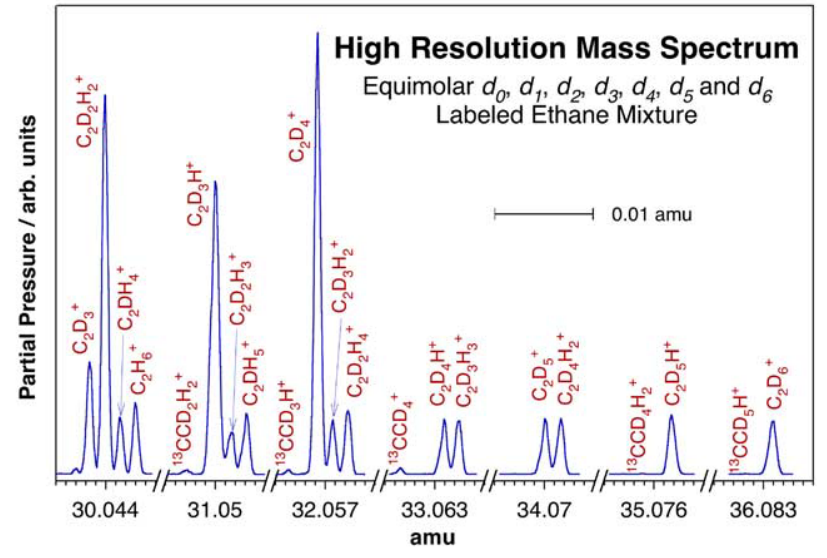

Figure 2. High-resolution mass spectra in the 30-36 Da range for an equimolar mixture of ethane- $d_{0},-d_{1},-d_{2},-d_{3},-d_{4},-d_{5}$, and $-d_{6}$. The instrument has enough resolving power to completely separate the contributions from the $\mathrm{C}_{2} \mathrm{X}_{6}{ }^{+}, \mathrm{C}_{2} \mathrm{X}_{5}{ }^{+}, \mathrm{C}_{2} \mathrm{X}_{4}^{+}$, and $\mathrm{C}_{2} \mathrm{X}_{3}{ }^{+}$ fragments $(X=H$ or $D)$ as well as those from ${ }^{13} \mathrm{C}$-substituted ions.

tion. The 30-36 Da data for the latter are displayed in Figure 2. It is clear that a complete separation of the $\mathrm{C}_{2} \mathrm{X}_{6}{ }^{+}, \mathrm{C}_{2} \mathrm{X}_{5}{ }^{+}, \mathrm{C}_{2} \mathrm{X}_{4}{ }^{+}$and $\mathrm{C}_{2} \mathrm{X}_{3}{ }^{+}$ions $(\mathrm{X}=\mathrm{H}$ or $\mathrm{D})$ in each $\mathrm{Da}$ region is possible with our instrumentation: notice, for instance, the individual peaks obtained for the $\mathrm{C}_{2} \mathrm{D}_{3}{ }^{+}, \mathrm{C}_{2} \mathrm{D}_{2} \mathrm{H}_{2}{ }^{+}, \mathrm{C}_{2} \mathrm{DH}_{4}{ }^{+}$and $\mathrm{C}_{2} \mathrm{H}_{6}{ }^{+}$fragments around the $30 \mathrm{Da}$ region (plus additional minor peaks for ${ }^{13} \mathrm{C}$-substituted moieties). This is particularly important in the analysis of ethanes, where most of the intensity in the mass spectra is not due to the molecular ions but to $\mathrm{C}_{2} \mathrm{X}_{4}{ }^{+}$fragments. The separation illustrated in Figure 2 makes the determination of sample compositions in terms of number of deuterium substitutions straightforward. The composition of the $37 \%$ conversion $\mathrm{C}_{2} \mathrm{H}_{6}+\mathrm{D}_{2}$ catalytic sample estimated with this technique is contrasted with that measured with LR-MS in Figure 1.

It was determined that the most promising procedure for the determination of the ratios of symmetric versus asymmetric isotopic substitutions in the ethane$d_{2},-d_{3}$, and $-d_{4}$ components of our gas mixtures would be via analysis of the signals corresponding to the $\mathrm{C}_{2} \mathrm{X}_{4}{ }^{+}$fragments in the HR mass spectra. For that, the mass spectrometry cracking pattern of all pure isotopologs was required, in particular that for $\mathrm{CH}_{2} \mathrm{DCH}_{2} \mathrm{D}$ (which we could not purchase or synthesize). The $\mathrm{C}_{2} \mathrm{X}_{4}{ }^{+}$contributions to the mass spectra of each ethane were calculated by using two parameters. First, the symmetric versus asymmetric $X_{2}$ removal ratio from $\mathrm{C}_{2} \mathrm{X}_{6}{ }^{+}$in the ionizer of the mass spectrometer (that is, one hydrogen/deuterium from each carbon versus both from the same carbon) was estimated at $0.84: 0.16$ by comparing the signals for $\mathrm{C}_{2} \mathrm{D}_{2} \mathrm{H}_{2}^{+}$versus $\mathrm{C}_{2} \mathrm{D}_{3} \mathrm{H}^{+}+$ $\mathrm{C}_{2} \mathrm{DH}_{3}{ }^{+}$obtained with $\mathrm{CD}_{3} \mathrm{CH}_{3}$. Second, an isotope effect for $\mathrm{H}$ versus $\mathrm{D}$ removal of 1.62 was measured by a collective minimum square fit of the calculated cracking patterns of all the pure compounds we had to those obtained experimentally. The resulting $\mathrm{C}_{2} \mathrm{X}_{4}{ }^{+}$distribu-

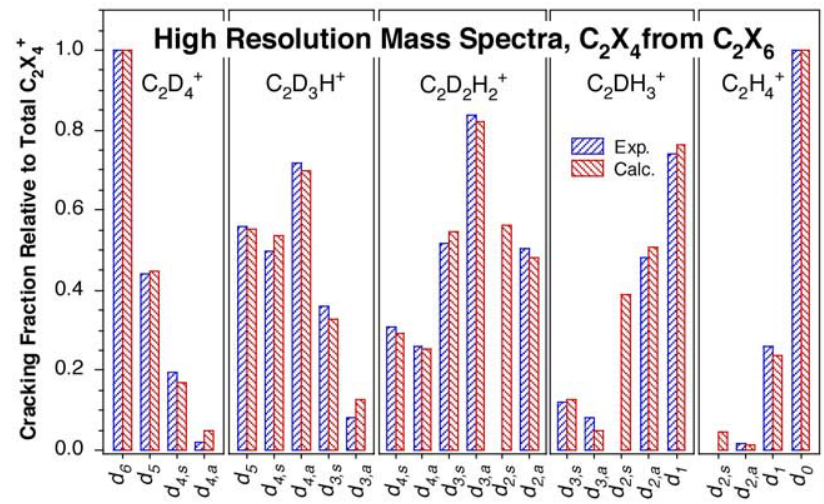

Figure 3. $\mathrm{C}_{2} \mathrm{X}_{4}{ }^{+}$formation probabilities after electron impact ionization of a number of pure ethane isotopologs in our highresolution mass spectrometer. The isotopologues are indicated in the $\mathrm{x}$ axis by the number of deuterium substitutions $\left(d_{\mathrm{n}}, \mathrm{a}=\right.$ asymmetric or $\mathrm{s}=$ symmetric). Both experimental results and calculated cracking patterns are provided for each compound. Excellent predictability could be obtained by using only two parameters, namely, the probability for symmetric versus asymmetric $\mathrm{X}_{2}$ extraction (0.84:0.16) and an isotope effect for $\mathrm{H}$ versus D abstraction (1.62).

tions for all ethanes are contrasted to the measured values in Figure 3. An excellent fit was obtained in all cases, with deviations rarely larger than $1-2 \%$, and never exceeding $\sim 5 \%$.

Unfortunately, the HR-MS approach turned out to be ineffective for the full analysis of our ethane mixtures. Several reasons can be provided to explain this failure. For one, the $\mathrm{C}_{2} \mathrm{X}_{4}{ }^{+}$yields obtained after ionization of the symmetrically- versus asymmetrically-substituted ethanes in the mass spectrometer are often fairly similar. Perhaps the best pairs of signals for the differentiation between the two ethane isotopologues are those for $\mathrm{C}_{2} \mathrm{D}_{4}{ }^{+}$from ethane- $d_{4}\left(19 \%\right.$ for $\mathrm{CD}_{2} \mathrm{HCD}_{2} \mathrm{H}$ versus $2 \%$ for $\left.\mathrm{CD}_{3} \mathrm{CDH}_{2}\right)$, and for $\mathrm{C}_{2} \mathrm{D}_{3} \mathrm{H}^{+}$from ethane- $d_{3}(36 \%$ for $\mathrm{CD}_{2} \mathrm{HCDH}_{2}$ versus $8 \%$ for $\left.\mathrm{CD}_{3} \mathrm{CH}_{3}\right)$, but those are exceptions rather than the rule. In addition, the $\mathrm{C}_{2} \mathrm{H}_{6}$, $\mathrm{C}_{2} \mathrm{H}_{5} \mathrm{D}, \mathrm{C}_{2} \mathrm{HD}_{5}$, and $\mathrm{C}_{2} \mathrm{D}_{6}$ isotopologues display quite high $\mathrm{C}_{2} \mathrm{X}_{4}{ }^{+}$intensities in their cracking patterns. The severity of this interference is compounded by the fact that ethane- $d_{0}$ and $-d_{6}$ are the main products in the catalytic mixtures.

As an example to illustrate these limitations of the HR-MS technique, lets consider the specific case of our $37 \%$ conversion $\mathrm{C}_{2} \mathrm{H}_{6}+\mathrm{D}_{2} / \mathrm{Pt}$ catalytic sample. In terms of the $\mathrm{C}_{2} \mathrm{DH}_{3}{ }^{+}$ion, it was determined that about $60 \%$ of its signal was due to the ethane- $d_{2}$ isotopologues. However, the difference in the cracking yield for that peak (relative to the main signal) between the symmetric and asymmetric isomers amounts to less than $1 \%$. An attempt to calculate the composition of the $\mathrm{C}_{2} \mathrm{D}_{2} \mathrm{H}_{4}$ isotopologue with those data resulted in a value of $135 \%$ for $\mathrm{CDH}_{2} \mathrm{CDH}_{2}$, clearly outside the physically possible range. Analysis of the $\mathrm{C}_{2} \mathrm{D}_{2} \mathrm{H}_{2}{ }^{+}$ion presented the opposite problem: the symmetric/asymmetric signal intensity ratio for that peak is about 1.5 , 
but since only $\sim 25 \%$ of the total $\mathrm{C}_{2} \mathrm{D}_{2} \mathrm{H}_{2}{ }^{+}$MS signal from the mixture is due to ethane- $d_{2}$ (the rest comes from ethane- $d_{3}$ and $-d_{4}$ ), large errors are introduced in the calculations as well; the percentage of the symmetric isomer was estimated here at $-20 \%$, again outside the possible range. We used our simulated spectra for $\mathrm{CDH}_{2} \mathrm{CDH}_{2}$ for these calculations (since we did not have access to the experimental spectrum of that compound), but we believe that this does not invalidate our arguments because (1) the simulated spectra of the other isotopologs matched quite reasonably the experimental patterns, and (2) our simulated cracking for the symmetric ethane- $d_{2}$ is consistent with mass spectrometric data reported in the past [10]. Ultimately, it was determined that a proper deconvolution of the $\mathrm{C}_{2} \mathrm{X}_{4}{ }^{+}$ signals from HR-MS experiments requires a degree of reproducibility in the intensities of the individual peaks of better than $0.1 \%$, well beyond the performance of our instrument [11].

Finally, the potential of MS/CID-MS to fully resolve the composition of the isotopically labeled ethane mixtures was probed. The promise of this tandem mass spectrometry technique is that while the first stage can be used to separate different isotopologues according to the extent of the $\mathrm{H}-\mathrm{D}$ exchange (the total number of hydrogens or deuteriums exchanged), the second can then focus on identifying the regiospecificity of those substitutions. For this, detailed data were acquired in the second stage for each of the peaks in the 30-36 Da range of the mass spectra of the ethanes obtained in the first stage of this MS/CID-MS. A typical second-stage spectrum recorded from these experiments is shown in Figure 4 , in this case for the $34 \mathrm{Da}$ signal from the first stage of the spectrum from the $55 \%$-exchanged $\mathrm{C}_{2} \mathrm{D}_{6}+$ $\mathrm{H}_{2}$ sample. Nice definition could be obtained in both the 24-36 $\left(\mathrm{C}_{2} \mathrm{X}_{\mathrm{n}}{ }^{+}\right)$and 12-18 $\left(\mathrm{CX}_{\mathrm{n}}{ }^{+}\right)$Da regions of the spectra. On the other hand, extensive dissociation of the ions filtered in the first MS stage does take place in the collision-induced (CID) region before the second. In fact, it was determined by using the pure ethane isotopologues available in this work that the cracking patterns obtained via collisions with the He gas in the second stage were quite similar to those recorded in the first, after electron impact (EI) ionization. This is illustrated in Figure 5 for the 24-36 Da region of the spectra obtained with $\mathrm{CD}_{2} \mathrm{HCH}_{3}, \mathrm{CD}_{3} \mathrm{CH}_{3}, \mathrm{CD}_{2} \mathrm{HCD}_{2} \mathrm{H}$, and $\mathrm{CD}_{3} \mathrm{CD}_{2} \mathrm{H}$. The main difference between the regular mass spectra of these compounds and the mass spectra obtained for their molecular ions in the second stage is that after the CID process a significantly higher signal is observed for the removal of normal hydrogen (rather than deuterium) during the decomposition of the $\mathrm{C}_{2} \mathrm{X}_{6}{ }^{+}$ ions to $\mathrm{C}_{2} \mathrm{X}_{4}{ }^{+}$fragments. This can help in the identification of symmetric versus asymmetric $\mathrm{H}-\mathrm{D}$ exchange, but makes the quantitative analysis of the $\mathrm{C}_{2} \mathrm{X}_{4}{ }^{+}$ions difficult. It should also be noted that the first MS stage of our instrument does not have enough resolving power to separate the different $\mathrm{C}_{2} \mathrm{X}_{\mathrm{n}}{ }^{+}$ions within a given mass unit so, for instance, the $34 \mathrm{Da}$ spectrum in

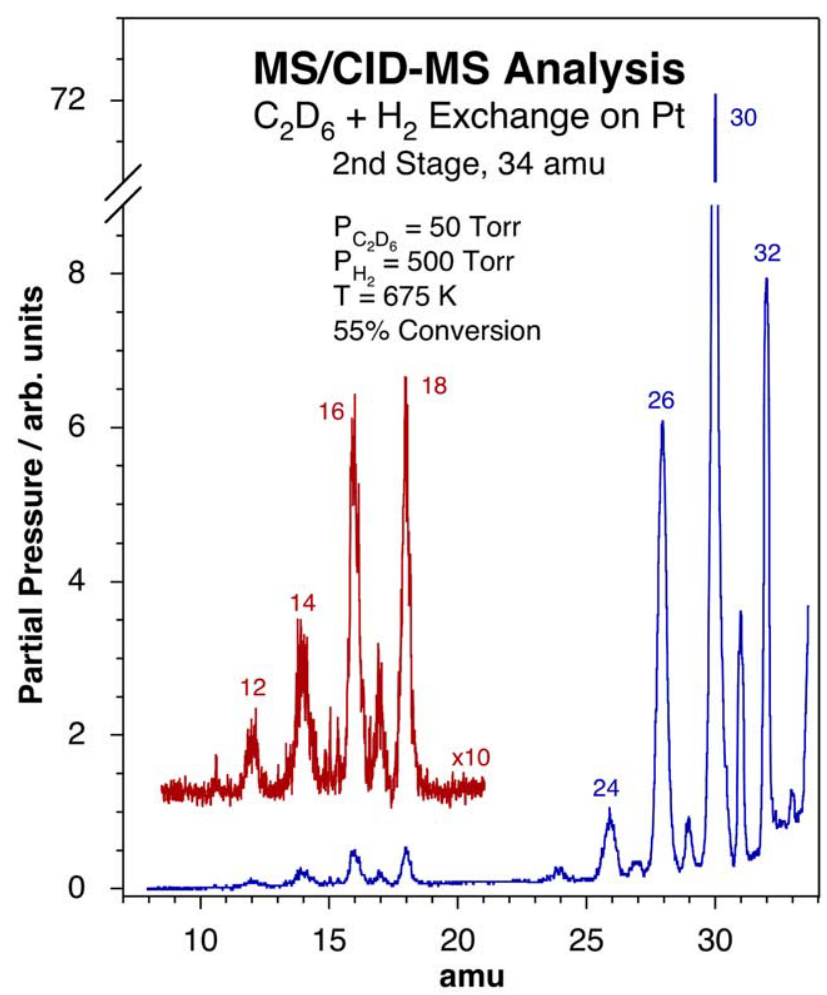

Figure 4. Tandem mass spectrometry/collision-induced decomposition mass spectrometry (MS/CID-MS) data from a 50 torr $\mathrm{C}_{2} \mathrm{D}_{6}+500$ torr $\mathrm{H}_{2}$ mixture after $55 \%$ of catalytic $\mathrm{H}-\mathrm{D}$ exchange on a platinum foil. The figure shows the results from a second mass resolution of the ionic fragments that result from $\mathrm{He}$ collision-induced dissociation of the $34 \mathrm{Da}$ ion isolated in the first stage of mass filtering. Clear signals could be recorded for both 24-36 $\left(C_{2} X_{n}+\right)$ and 12-18 $\left(\mathrm{CX}_{n}^{+}\right)$Da regions of the spectra.

Figure 4 includes contributions not only from $\mathrm{C}_{2} \mathrm{D}_{4} \mathrm{H}_{2}{ }^{+}$ but also from $\mathrm{C}_{2} \mathrm{D}_{5}{ }^{+}$fragments. This problem is more acute with the peak for the $32 \mathrm{Da}$ fragment, which could

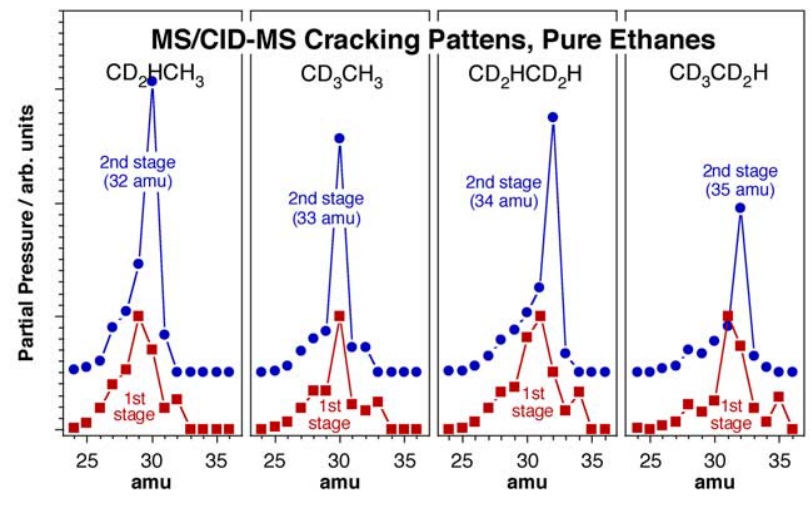

Figure 5. First- and second-stage cracking patterns for four different pure ethane isotopologues (from left to right, $\mathrm{CD}_{2} \mathrm{HCH}_{3}$, $\mathrm{CD}_{3} \mathrm{CH}_{3}, \mathrm{CD}_{2} \mathrm{HCD}_{2} \mathrm{H}$, and $\left.\mathrm{CD}_{3} \mathrm{CD}_{2} \mathrm{H}\right)$ in the 24-36 Da region, obtained with our tandem MS/CID-MS setup. Fairly similar patterns are obtained in both stages (after electron- and collisioninduced activation, respectively), except for the enhanced formation of $\mathrm{C}_{2} \mathrm{X}_{4}{ }^{+}$fragments by normal hydrogen abstraction seen in the second (CID) case. 
Table 1. Second-stage $\mathrm{CX}_{n}{ }^{+}$cracking patterns obtained with our MS/CID-MS instrument for all different isotopologues of ethane

\begin{tabular}{|c|c|c|c|c|c|c|c|c|c|c|}
\hline & \multicolumn{2}{|c|}{$14 \mathrm{Da}$} & \multicolumn{2}{|c|}{$15 \mathrm{Da}$} & \multicolumn{2}{|c|}{$16 \mathrm{Da}$} & \multicolumn{2}{|c|}{$17 \mathrm{Da}$} & \multicolumn{2}{|c|}{$18 \mathrm{Da}$} \\
\hline & $\operatorname{Exp}^{a}$ & Calc. $^{\mathrm{b}}$ & $\operatorname{Exp}^{a}$ & Calc. $^{b}$ & $\operatorname{Exp}^{a}$ & Calc. $^{\mathrm{b}}$ & $\operatorname{Exp}^{a}$ & Calc. $^{b}$ & $\operatorname{Exp}^{a}$ & Calc. $^{b}$ \\
\hline $\mathrm{CH}_{3} \mathrm{CH}_{3}$ & 0.35 & 0.34 & 1.00 & 1.00 & 0.00 & 0.00 & 0.00 & 0.00 & 0.00 & 0.00 \\
\hline $\mathrm{CDH}_{2} \mathrm{CH}_{3}$ & 0.20 & 0.26 & 0.52 & 0.57 & 0.50 & 0.50 & 0.00 & 0.00 & 0.00 & 0.00 \\
\hline $\mathrm{CD}_{2} \mathrm{HCH}_{3}$ & 0.17 & 0.21 & 0.47 & 0.61 & 0.36 & 0.13 & 0.50 & 0.50 & 0.00 & 0.00 \\
\hline $\mathrm{CDH}_{2} \mathrm{CDH}_{2}$ & - & 0.15 & - & 0.27 & - & 1.00 & - & 0.02 & - & 0.00 \\
\hline $\mathrm{CD}_{3} \mathrm{CH}_{3}$ & 0.14 & 0.23 & 0.30 & 0.50 & 0.20 & 0.22 & 0.09 & 0.09 & 0.50 & 0.50 \\
\hline $\mathrm{CD}_{2} \mathrm{HCDH}_{2}$ & - & 0.11 & - & 0.23 & - & 0.57 & - & 0.50 & - & 0.00 \\
\hline $\mathrm{CD}_{3} \mathrm{CDH}_{2}$ & - & 0.13 & - & 0.11 & - & 0.67 & - & 0.03 & - & 0.50 \\
\hline $\mathrm{CD}_{2} \mathrm{HCD}_{2} \mathrm{H}$ & 0.09 & 0.08 & 0.18 & 0.23 & 0.21 & 0.15 & 1.00 & 1.00 & 0.06 & 0.02 \\
\hline $\mathrm{CD}_{3} \mathrm{CD}_{2} \mathrm{H}$ & 0.09 & 0.09 & 0.05 & 0.11 & 0.24 & 0.22 & 0.43 & 0.49 & 0.50 & 0.50 \\
\hline $\mathrm{CD}_{3} \mathrm{CD}_{3}$ & 0.11 & 0.12 & 0.00 & 0.00 & 0.36 & 0.34 & 0.00 & 0.00 & 1.00 & 1.00 \\
\hline
\end{tabular}

aThe experimental data correspond to the 14-18 Da region of the mass spectra obtained for the molecular ions after collision-induced dissociation with He gas.

bThe calculated patterns were obtained using the parameters discussed in the text.

ideally provide information about the composition of the ethane- $d_{2}$ products in the $\mathrm{H}-\mathrm{D}$ exchange mixtures, but which also include large contributions from $\mathrm{C}_{2} \mathrm{D}_{4}{ }^{+}$ and $\mathrm{C}_{2} \mathrm{D}_{3} \mathrm{H}_{2}{ }^{+}$ions (see Figure 2). The use of the signals from the $\mathrm{C}_{2} \mathrm{X}_{4}{ }^{+}$fragments in these second-stage MS spectra for the determination of symmetric versus asymmetric $\mathrm{H}-\mathrm{D}$ exchange was deemed not viable.

Instead, focus was placed on the use of the peaks corresponding to the $\mathrm{CX}_{\mathrm{n}}{ }^{+}$ions, the methyl cations in particular. The 12-18 Da region of the second-stage MS/CID-MS spectra was deconvoluted by using three parameters extracted from the data from the pure ethane isotopologues: (1) the probability for the loss of one hydrogen atom in the second stage, $\mathrm{CH}_{\mathrm{n}}{ }^{+} \rightarrow$ $\mathrm{CH}_{\mathrm{n}-1}{ }^{+}$, estimated at $\mathrm{P}_{-\mathrm{H}, 2}=0.34$ (independent of $\mathrm{n}, \mathrm{n}$ $=3,2$, or 1 , and a bit lower than in the first stage, where $\left.\mathrm{P}_{-\mathrm{H}, 1}=0.48\right)$; (2) the probability for an exchange of a deuterium with a hydrogen atom, $\mathrm{CD}_{\mathrm{n}} \mathrm{H}_{3-\mathrm{n}}{ }^{+} \rightarrow$ $\mathrm{CD}_{\mathrm{n}-1} \mathrm{H}_{4-\mathrm{n}}{ }^{+}\left(\mathrm{n}=3,2\right.$, or 1), $\mathrm{P}_{\mathrm{D} \rightarrow \mathrm{H}, 2}=0.58$; and (3) the reverse exchange of a hydrogen with a deuterium, $\mathrm{CD}_{\mathrm{n}} \mathrm{H}_{3-\mathrm{n}}{ }^{+} \rightarrow \mathrm{CD}_{\mathrm{n}+1} \mathrm{H}_{2-\mathrm{n}}{ }^{+}(\mathrm{n}=2,1$, or 0$), \mathrm{P}_{\mathrm{H} \rightarrow \mathrm{D}, 2}=$ 0.31 . The final results for the $\mathrm{CX}_{\mathrm{n}}{ }^{+}$cracking products from the pure ethane isotopologues are reported in Table 1. A reasonable agreement between experiments and calculations was obtained.

One interesting observation worth highlighting here in connection with the MS/CID-MS experiments is the fact that the decomposition of a given ion in the second stage always yields the same cracking pattern regardless of the original molecule from which that ion originates in the first stage. In particular, the $\mathrm{C}_{2} \mathrm{D}_{5}{ }^{+}$ion from ethane- $d_{6}$ and ethane- $d_{5}$ (and presumably the $\mathrm{C}_{2} \mathrm{H}_{5}{ }^{+}$ion from ethane- $d_{1}$ and ethane- $d_{0}$ ) yield the same 34 and $32 \mathrm{Da}(29$ and $28 \mathrm{Da}$ ) spectra in the second stage, respectively. Perhaps more importantly, the $\mathrm{C}_{2} \mathrm{D}_{4}{ }^{+}$ion from all $\mathrm{CD}_{3} \mathrm{CD}_{3}, \mathrm{CD}_{3} \mathrm{CD}_{2} \mathrm{H}$, and $\mathrm{CD}_{2} \mathrm{HCD}_{2} \mathrm{H}$ yields the same cracking pattern as well. This helps in the analysis of the second-stage spectra, because only a few ions need to be considered regardless of the number of ethane isotopologues that contribute to the signal. On the other hand, ions such as $\mathrm{C}_{2} \mathrm{D}_{4} \mathrm{H}^{+}$can exist as either one of two possible isomers $\left(\mathrm{CD}_{3} \mathrm{CDH}^{+}\right.$and $\mathrm{CD}_{2} \mathrm{HCD}_{2}{ }^{+}$), and those can in principle yield different cracking patterns. It was found experimentally that this is the case in the 24-36 Da range of the second-stage MS spectra, but not so much in the $\mathrm{CX}_{\mathrm{n}}{ }^{+}$region.

The cracking probability data reported in Table 1 was used to analyze the ethane mixtures obtained in our $\mathrm{H}-\mathrm{D}$ catalytic exchange experiments. Figure 6 displays the results pertinent to the products from two isotopic substitutions. The left panel corresponds to the analysis of the spectrum in Figure 4, that of the collision-induced dissociation of the $34 \mathrm{Da}$ ions from the mass spectrum of the sample obtained by conversion of the $\mathrm{C}_{2} \mathrm{D}_{6}+\mathrm{H}_{2}$ mixture, while the one on the right

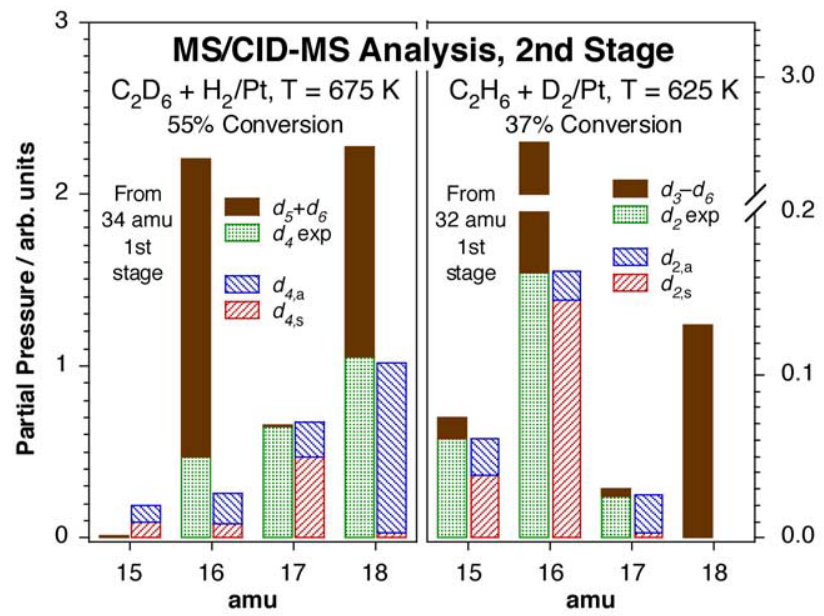

Figure 6. Determination of the relative contributions from symmetric and asymmetric $\mathrm{H}-\mathrm{D}$ substitutions in the doubly-exchange products from reactions between $\mathrm{C}_{2} \mathrm{D}_{6}+\mathrm{H}_{2}$ (left) and $\mathrm{C}_{2} \mathrm{H}_{6}+\mathrm{D}_{2}$ (right) mixtures. The left bars show the raw and corrected 34 (first mixture) and 32 (second) Da MS/CID-MS data in the 15-18 Da region, before and after subtraction of the contributions from species other than the doubly-substituted ethanes of interest. The right bars correspond to the best fits to the data using appropriate combinations of the symmetric and asymmetric components, and amounts to $70 \% \mathrm{CD}_{3} \mathrm{CDH}_{2}: 30 \% \mathrm{CD}_{2} \mathrm{HCD}_{2} \mathrm{H}$ and $25 \% \mathrm{CD}_{2} \mathrm{HCH}_{3}$ : $75 \% \mathrm{CDH}_{2} \mathrm{CDH}_{2}$ mixtures, respectively. 


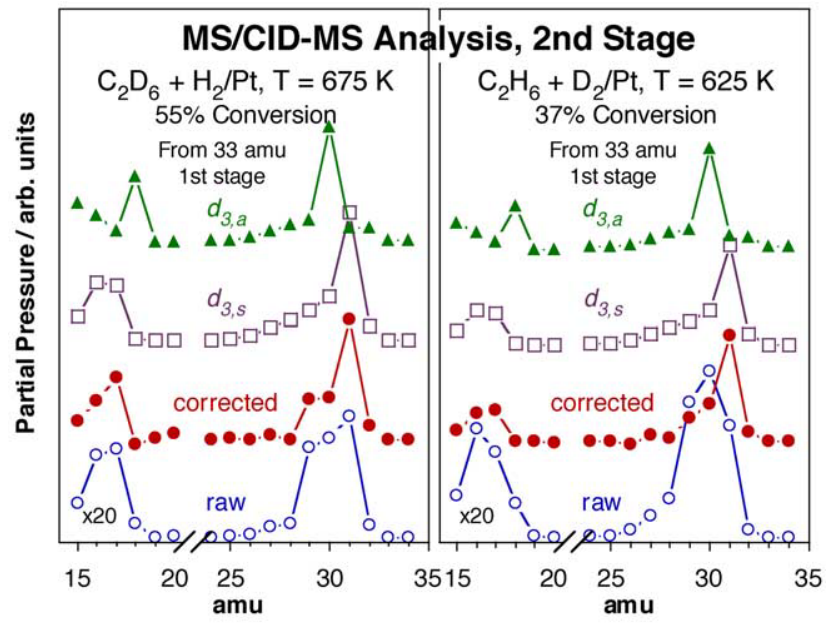

Figure 7. 33 Da MS/CID-MS data for the same mixtures reported in Figure 6. Comparison of the spectra from the reaction samples, original (raw) and after subtraction of the contributions from ethane- $d_{4}$ and $-d_{5}$ (corrected), with those from pure $\mathrm{CD}_{2} \mathrm{HCDH}_{2}$ (symmetric ethane- $d_{3}$ ) and $\mathrm{CD}_{3} \mathrm{CH}_{3}$ (asymmetric ethane- $d_{3}$ ) indicates the prevalence of symmetric $\mathrm{H}-\mathrm{D}$ exchange in the triply-substituted ethanes of those mixtures. Notice in particular the lack of significant signals for 15, 18, and 30 Da characteristic of $\mathrm{CD}_{3} \mathrm{CH}_{3}$.

reports the results using the $32 \mathrm{Da}$ MS/CID-MS data for the case of the $\mathrm{C}_{2} \mathrm{H}_{6}+\mathrm{D}_{2}$ experiment. In both cases the left bars provided for each of the 15-18 Da fragments indicate the partition of the total measured signal between the species of interest (ethane- $d_{4}$ and ethane- $d_{2}$, respectively) and the other ethane isotopologues. The right bars then display the partition between the symmetric and asymmetric components that best fit the data.

It can be seen in Figure 6 that reasonable results could be obtained for both of the samples analyzed. The best fits to the experimental data correspond to $70 \%$ $\mathrm{CD}_{3} \mathrm{CDH}_{2}: 30 \% \mathrm{CD}_{2} \mathrm{HCD}_{2} \mathrm{H}$ and $25 \% \mathrm{CD}_{2} \mathrm{HCH}_{3}: 75 \%$ $\mathrm{CDH}_{2} \mathrm{CDH}_{2}$ mixtures, respectively. At first sight it would appear that the fit for the second case is better than that for the first (notice in particular the large deviations between the experimental and calculated values of the 15 and $16 \mathrm{Da}$ signals for the $\mathrm{C}_{2} \mathrm{D}_{6}+\mathrm{H}_{2}$ mixture). However, some additional uncertainty is introduced in the experiment with the light alkane because of the large signals from the $\mathrm{C}_{2} \mathrm{D}_{4}{ }^{+}$ion (responsible for $\sim 95 \%$ of the intensity of the 16 Da peak). In any case, the results for the $\mathrm{C}_{2} \mathrm{H}_{6}+\mathrm{D}_{2}$ mixture are in excellent agreement with previous analysis using ${ }^{13} \mathrm{C}$ $\operatorname{NMR}\left(30 \% \mathrm{CD}_{2} \mathrm{HCH}_{3}: 70 \% \mathrm{CDH}_{2} \mathrm{CDH}_{2}\right)[7,12]$.

Additional analysis of the ethane- $d_{3}$ composition in both cases was done with the aid of the data in Figure 7. A complete quantitative analysis is hindered in this case by the large contributions to these second-stage MS spectra from other ethane isotopologues. On the other hand, clear semi-quantitative conclusions can be reached by simple inspection of the cracking patterns, in particular because of the clear differences in the
24-36 Da region between the spectra of $\mathrm{CD}_{2} \mathrm{HCDH}_{2}$ $\left(d_{3, \mathrm{~s}}\right)$ and $\mathrm{CD}_{3} \mathrm{CH}_{3}\left(d_{3, \mathrm{a}}\right)$. Notice, for instance, the predominance of the peaks at 30 and $31 \mathrm{Da}$ in the asymmetric and symmetric cases, respectively, and also their corresponding intense peaks at 15 and $18\left(\mathrm{CH}_{3}{ }^{+}\right.$and $\left.\mathrm{CD}_{3}{ }^{+}\right)$versus 16 and $17\left(\mathrm{CDH}_{2}{ }^{+}\right.$and $\left.\mathrm{CD}_{2} \mathrm{H}^{+}\right) \mathrm{Da}$. The second-stage MS/CID-MS spectra from both mixtures show, after correcting for the contributions from the other isotopologs (ethane- $d_{4}$ and $-d_{5}$, leading to the traces labeled "corrected"), strong peaks at 16, 17, and $31 \mathrm{Da}$, and negligible remaining intensities ascribable to asymmetric ethane- $d_{3}$. The analysis of the components due to four $\mathrm{H}-\mathrm{D}$ exchanges is even more uncertain, but also points to a predominance of symmetrically substituted isotopologues.

\section{Discussion}

The ability to detect the specific moiety where a particular deuterium substitution takes place within an organic molecule is an invaluable tool for the study of the mechanisms of chemical reactions. The interest in our case has been to determine the regioselectivity of the elimination of hydrogen atoms from alkyl groups adsorbed on metal surfaces [13], as this defines the overall selectivity of many catalytic processes of commercial interest such as oil processing and fine chemical and pharmaceutical manufacturing [14, 15]. It has been our contention that although hydride elimination from the $\beta$ carbon (the second counting from the surface) of key alkyl surface intermediates is often the most prevalent, this only explains the rapid alkane-alkene equilibria typically observed in catalytic reactions under reducing conditions $[16,17]$. In order to promote other more important pathways such as isomerizations, cyclizations, and aromatizations, removal of hydrogen atoms from other positions across the hydrocarbon chain is required. Based mostly on experiments carried out with model single-crystal surfaces and under vacuum [18], we have suggested that carbon skeletal rearrangements require a $\gamma$-hydride elimination step, and that elimination at the $\alpha$ position is to be avoided because it leads to undesirable $\mathrm{C}-\mathrm{C}$ bond breaking (hydrogenolysis) side reactions $[19,20]$.

$\mathrm{H}-\mathrm{D}$ exchange studies are ideally suited to test our hypothesis because they provide direct evidence for the relative lability of the different hydrogens in a given reactant under realistic catalytic conditions. In particular, the results from the studies reported here indicate that, after an initial activation of the ethane reactant by the platinum catalyst to produce an ethyl surface intermediate, the second hydrogen removal takes place preferentially at the $\beta$ carbon. Subsequent rehydrogenation (dideuteriation) of the resulting adsorbed ethylene then leads to the predominant production of symmetrically substituted doubly exchanged ethane. This is consistent with our previous observations on model systems $[15,21]$. On the other hand, it is also clear that a sizable amount of asymmetrically exchanged prod- 
ucts are made in these reactions as well. This indicates that, under the pressures and temperatures used for hydrocarbon catalytic conversion, $\alpha$-hydride elimination may compete with dehydrogenation at the $\beta$ position [22]. Such competition explains the ability for platinum to promote hydrocarbon reforming processes. Further experiments with longer-chain reactants suggest that elimination from the $\gamma$ position is also possible, but it would be nice to obtain direct confirmation of this via $H-D$ catalytic exchange studies of appropriate molecules such as neopentane [22-24].

The work presented here was carried out with a simple molecule, ethane, and for a specific purpose, that of elucidating the mechanism of alkane conversions on metal catalysts. However, the ideas presented are quite general, and can be easily extended to more complex molecules and to different applications [25-28]. It should be noted that there are alternative methods for the determination of isotopic substitutions. In particular, we were quite successful in the past with the characterization of our ethane mixtures using NMR [7, 12]. Nevertheless, we see the two approaches as complementary. For instance, the best results in our NMR studies were obtained by using the signals from the ${ }^{13} \mathrm{C}$ nuclei, since both ${ }^{1} \mathrm{H}$ and ${ }^{2} \mathrm{H}$ NMR spectra proved too complex for proper analysis. The ${ }^{13} \mathrm{C}$ NMR data were fairly straightforward to analyze, but worked best with ${ }^{13} \mathrm{C}$-enriched samples, which yield stronger signals and thus minimize problems due to lack of sensitivity. The requirement of such isotopically enriched compounds can prove expensive at best, and difficult from the synthetic point of view in many instances.

It should also be pointed out that although the molecule studied here, ethane, is quite simple, the complexity of our problem arose from the need to analyze full isotopologue mixtures where the products of interest constituted minor components. Both regular mass spectrometry and NMR are excellent probes to identify specific moieties within a given molecule, but not so well suited for the separation of mixtures. Chromatography, alone or in combination with mass spectrometry, could in principle be used for this purpose [29], but it is not an easy technique to implement for the separation of isotopologues. The power of tandem mass spectrometry is that it can be easily adapted for such separations. Although there are limitations due to the interference of major cracking fragments in the first stage of filtering $\left(\mathrm{C}_{2} \mathrm{X}_{4}{ }^{+}\right.$ions in our case), MS/ CID-MS allows for the separation of molecules with different numbers of deuterium substitutions for further analysis in the second stage. The same idea is clearly applicable to mixtures of more complex molecules.

The other clear advantage of MS/CID-MS is that it is often simple to interpret, especially if semi-quantitative information on the regiospecificity of the substitutions is all that is required. It is known that the cracking patterns in CID-MS are highly dependent on the conditions used, especially in terms of the estimation of the relative intensities [27]. Nevertheless, it was shown above that at least the general features of those patterns can be predicted by using only a handful of parameters. Although advantage was taken here of the availability of most of the ethane isotopologues to obtain individual cracking patterns, this was shown to not be indispensable. Moreover, some determinations could be made by using common sense, without the need to measure any cracking patterns at all. For instance, the absence of any significant intensity for $18 \mathrm{Da}$ (the $\mathrm{CD}_{3}{ }^{+}$fragment) in the spectra of the mixtures in Figure 7 is a clear indication of the lack of detectable $\mathrm{CD}_{3} \mathrm{CH}_{3}$. Similarly, the low intensities in the 15 and 17 Da regions of the second-stage mass spectra of the $32 \mathrm{Da}$ ion was used in our previous report to argue for the limited production of $\mathrm{CD}_{2} \mathrm{HCH}_{3}$ from $\mathrm{C}_{2} \mathrm{H}_{6}+\mathrm{D}_{2}$ mixtures. It helps to know that only limited isotopic scrambling takes place during the scission of the $\mathrm{C}-\mathrm{C}$ bond in the CID region of the instrument.

In summary, we believe that tandem MS/CID-MS is a useful technique for the analysis of mixtures of isotope-substituted compounds. It offers complementary information to other analytical techniques such as NMR often used for this task. Indeed, both MS/CID-MS and NMR have been used extensively for the identification of isotopic substitutions in individual molecules in connection with structural determinations [30-32]. Our results indicate the usefulness of tandem mass spectrometry for a less common application, that of quantifying the composition of mixtures of isotopologues. High-resolution mass spectrometry proved less successful for this application.

\section{Acknowledgments}

Funds for this work were provided by a grant from the National Science Foundations. The authors thank Dr. Richard Kondrat for his help with the data acquisition.

\section{References}

1. Thomas, A. F. Deuterium Labeling in Organic Chemistry; Appleton-Century-Crofts: New York, 1971.

2. Ozaki, A. Isotopic Studies of Heterogeneous Catalysis, Kodansha/Academic Press: Tokyo and New York, 1977.

3. Vederas, J. C. The Use of Stable Isotopes in Biosynthetic Studies. Nat. Prod. Rep. 1987, 4, 277-337.

4. De Meer, K. M; Roef, M. J.; Kulik, W.; Jakobs, C. In Vivo Research with Stable Isotopes in Biochemistry, Nutrition, and Clinical Medicine. An Overview. Isotop. Environ. Health Studies 1999, 35, 19-37.

5. Heumann, K. G. Isotopic Analyses of Inorganic and Organic Substances by Mass Spectrometry. Int. J. Mass Spectrom. 1982, 45, 87-110.

6. Dienes, T.; Pastor, S. J.; Schurch, S.; Scott, J. R.; Yao, J.; Cui, S. L.; Wilkins, C. L. Fourier Transform Mass SpectrometryAdvancing Years (1992 Mid 1996). Mass Spectrom. Rev. 1996, $15,163-211$.

7. Loaiza, A.; Xu, M.; Zaera, F. On the Mechanism of the H-D Exchange Reaction in Ethane over Platinum Catalysts. J. Catal. 1996, 159, 127-139. 
8. Aryafar, M.; Zaera, F. Kinetic Study of the Catalytic Oxidation of Alkanes over Nickel, Palladium, and Platinum Foils. Catal. Lett. 1997, 48, 173-183.

9. Ali, A. H.; Zaera, F. Kinetic Study on the Selective Catalytic Oxidation of 2-Propanol to Acetone over Nickel Foils. J. Mol. Catal. A 2002, 177, 215-235.

10. Amenomiya, Y.; Pottie, R. F. Mass Spectra of Some Deuteriated Ethanes. II. An Empirical Method of Calculation of the Spectra. Can. J. Chem. 1968, 46, 1741-1746.

11. Vidavsky, I.; Gross, M. L. In Handbook of Instrumental Techniques for Analytical Chemistry; Settle, F., Ed.; Prentice Hall: Upper Saddle River, NJ, 1997; pp 589-608.

12. Loaiza, A.; Borchardt, D.; Zaera, F. An NMR Method for the Analysis of Mixtures of Alkanes with Different Deuterium Substitutions. Spectrochim. Acta A 1997, 53, 2481-2493.

13. Zaera, F. An Organometallic Guide to the Chemistry of Hydrocarbon Moieties on Transition Metal Surfaces. Chem. Rev. 1995, 95, 2651-2693.

14. Zaera, F. Outstanding Mechanistic Questions in Heterogeneous Catalysis. J. Phys. Chem. B 2002, 106, 4043-4052.

15. Zaera, F. Surface Chemistry of Hydrocarbon Fragments on Transition Metals: Towards Understanding Catalytic Processes. Catal. Lett. 2003, 91, 1-9.

16. Zaera, F. On the Mechanism for the Hydrogenation of Olefins on Transition-Metal Surfaces: The Chemistry of Ethylene on Pt(111). Langmuir 1996, 12, 88-94.

17. Zaera, F. The Surface Chemistry of Hydrocarbons on Transition Metal Surfaces: A Critical Review. Isr. J. Chem. 1998, 38 293-311.

18. Zaera, F. Probing Catalytic Reactions at Surfaces. Prog. Surf. Sci. 2001, 69, 1-98.

19. Zaera, F. Tjandra, S. The Thermal Chemistry of Neopentyl Iodide on $\mathrm{Ni}(100)$ Surfaces: Selectivity between $\alpha-\mathrm{C}-\mathrm{H}$ and $\gamma-\mathrm{C}-\mathrm{H}$ and between $\mathrm{C}-\mathrm{H}$ and $\mathrm{C}-\mathrm{C}$ Bond-Scission Steps in Chemisorbed Neopentyl Moieties. J. Am. Chem. Soc. 1996, 118, 12738-12746.

20. Zaera, F. Selectivity in Hydrocarbon Catalytic Reforming: A Surface Chemistry Perspective. Appl. Catal. A 2002, 229, 75-91.

21. Zaera, F. Preparation and Reactivity of Alkyl Groups Adsorbed on Metal Surfaces. Acc. Chem. Res. 1992, 25, 260-265.
22. Zaera, F.; Tjandra, S.; Janssens, T. V. W. Selectivity Among Dehydrogenation Steps for Alkyl Groups on Metal Surfaces: Comparison Between Nickel and Platinum. Langmuir 1998, 14, 1320-1327.

23. Davis, S. M.; Gillespie, W. D.; Somorjai, G. A. Deuterium Isotope Effects for Hydrocarbon Reactions Catalyzed Over Platinum Single Crystal Surfaces. J. Catal. 1983, 83, 131-140.

24. Brown, R.; Kemball, C.; Oliver, J. A.; Sadler, I. H. The Use of Deuterium NMR Spectroscopy in Mechanistic Studies of Alkane-Eexchange Reactions on Supported Platinum and Rhodium Catalysts. J. Chem. Res. (1985, M), 3201-3246.

25. Lambert, J. B.; Shurvell, H. F.; Lightner, D. A.; Cooks, R. G. Organic Structural Spectroscopy; Prentice Hall: Upper Saddle River, NJ, 1998.

26. McLafferty, F. W. Tandem Mass Spectrometric Analysis of Complex Biological Mixtures. Int. J. Mass Spectrom. 2001, 212, 81-87.

27. Kienhuis, P. G. M.; Geerdink, R. B. A Mass Spectral Library Based on Chemical Ionization and Collision-Induced Dissociation. J. Chromatogr. A 2002, 974, 161-168.

28. Yinon, J. Advances in Forensic Applications of Mass Spectrometry, 2nd ed.; CRC Press: Boca Raton, FL, 2004.

29. Williams, J. D.; Burinsky, D. J. Mass Spectrometric Analysis of Complex Mixtures Then and Now: The Impact of Linking Liquid Chromatography and Mass Spectrometry. Int. J. Mass Spectrom. 2001, 212, 111-133.

30. Murata, M.; Izumikawa, M.; Tachibana, K.; Fujita, T.; Naoki, $\mathrm{H}$. Labeling Pattern of Okadaic Acid from ${ }^{18} \mathrm{O}_{2}$ and $\left[{ }^{18} \mathrm{O}_{2}\right]$ Acetate Elucidated by Collision-Induced Dissociation Tandem Mass Spectrometry. J. Am. Chem. Soc. 1998, 120, 147-151.

31. Deng, Y. Z.; Pan, H.; Smith, D. L. Selective Isotope Labeling Demonstrates that Hydrogen Exchange at Individual Peptide Amide Linkages Can be Determined by Collision-Induced Dissociation Mass Spectrometry. J. Am. Chem. Soc. 1999, 121, 1966-1967.

32. Kim, M. Y.; Maier, C. S.; Reed, D. J.; Deinzer, M. L. Site-Specific Amide Hydrogen/Deuterium Exchange in E-coli Thioredoxins Measured by Electrospray Ionization Mass Spectrometry. J. Am. Chem. Soc. 2001, 123, 9860-9866. 